\title{
EDUCAÇÃO PARA A PRÁXIS: CONTRIBUIÇÕES DE GRAMSCI PARA UMA PEDAGOGIA DA EDUCAÇÃO PROFISSIONAL
}

\author{
Eraldo Leme Batista ${ }^{1}$ \\ Hélica Silva Carmo Gomes ${ }^{2}$
}

\begin{abstract}
RESUMO
Nas últimas décadas, o modelo de educação profissional no Brasil tem passado por reestruturações em sua pedagogia, na tentativa de redirecionar o modelo tradicional de qualificação e conceber uma renovada formação para o trabalho. A atual proposta pedagógica visa atender ao máximo a demanda do mercado de trabalho e passa a adotar para o ensino neologismos como empregabilidade, competência, polivalência, competitividade e trabalho em equipe. Em um contexto de reestruturações produtivas, surge a pedagogia da competência, destinada a educar futuros trabalhadores de acordo com os parâmetros da produção capitalista.
\end{abstract}

Palavras - chave: Educação profissional; Práxis; Empregabilidade.

\section{EDUCATION FOR PRAXIS: GRAMSCI CONTRIBUTIONS TO A PEDAGOGY OF VOCATIONAL EDUCATION}

\begin{abstract}
In recent decades, the professional education model in Brazil has undergone restructuring in his pedagogy, in an attempt to redirect the traditional model of qualification and develop a renewed training for the job. The current pedagogical proposal aims to meet the most out of the labor market demand and will adopt for neologisms education as employability, competence, versatility, competitiveness and teamwork. In a context of productive restructuring, the pedagogy of competence arises, designed to educate future workers according to the parameters of capitalist production.

Keywords: Professional Education, Praxis, Employability.
\end{abstract}

As mudanças que ocorrem na educação profissional visam adequar, cada vez mais, a educação às exigências do mercado de trabalho, restringindo a abrangência deste ensino. Para melhor compreendê-las, torna-se necessário, portanto, questionar, relacionar e refletir os acontecimentos históricos e atuais, que norteiam a formação do trabalhador. Com este objetivo, o presente capítulo discute brevemente o paradigma de educação profissional adotado no país e suas consequências para a formação do trabalhador, em contrapartida, aponta-se a filosofia da práxis e a escola unitária de Gramsci como caminhos possíveis para recriar a educação profissional no país. 
A proposta da pedagogia da competência, instaurada na década de 1990, tem inspiração no Toyotismo, modo de organização e produção do trabalho, cujas características mais relevantes são: mecanização flexível; política de controle de qualidade; gerência participativa; multifuncionalização de mão de obra e sistema just in time (minimização dos estoques). No Toyotismo, exige-se o perfil de homem flexível e polivalente, para trabalhar em rotatividade de funções, assim como trabalhadores rápidos e eficazes preparados para agir em situações imprevistas. Desse modo, a pedagogia da educação profissional é pensada de forma a atender essas demandas de formação advindas do modo de produção capitalista em vigor.

Segundo pesquisa realizada por Gomes (2007), sobre o atual sistema pedagógico adotado nos cursos técnicos por duas principais escolas profissionalizantes do sistema $\mathrm{S}$, a influência do ideário toyotista, assim como da racionalidade técnica e do pragmatismo, estão presentes na organização curricular, na metodologia de ensino e no sistema de avaliação dessas instituições. As escolas pesquisadas, adotaram a pedagogia das competências, cujo objetivo é educar o sujeito utilizando um currículo que promova o desenvolvimento de competências individuais e coletivas para o trabalho, nos moldes do toyotismo.

Na pedagogia da competência, prega-se a importância da qualificação e defende que a formação de profissionais competentes é a chave para a empregabilidade. Estabelece-se, assim, uma relação causal direta entre educação e emprego, omitindo qualquer outro fator, seja este de ordem econômica, política ou social. Para Gomes (2007), ao se mistificar a questão da empregabilidade, a pedagogia da competência é fetichizada. Este fetichismo, que se ancora no individualismo, acaba por responsabilizar os sujeitos (alunos) pela inserção no mercado de trabalho, como se dependesse exclusivamente deles tornarem-se empregáveis ou não.

Uma vez fetichizada pelo discurso da empregabilidade, a educação profissional contribui para manutenção da lógica da racionalidade técnica, que segundo Klovdahl (1996) é inerente à lógica capitalista, que visa o aperfeiçoamento científico em prol do desenvolvimento econômico, reafirmando a crença de que ciência e tecnologia, podem e devem elevar consideravelmente a economia de um país. Assim, a formação do trabalhador fica restrita à preparação para atuação no mercado de trabalho, omitindo-se no currículo, conteúdos importantes para compreensão histórica das relações sociais e econômicas, que segundo Saviani (2007) são saberes importante para participação social dos sujeitos, advindos de uma pedagogia crítica social dos conteúdos, fundamental para a formação política desses futuros trabalhadores.

Outro princípio presente na pedagogia da competência é o da praticidade. Nesse aspecto, apreende-se, nas bases constituintes da pedagogia da competência, o menosprezo pelas abstrações, a ênfase na ação, nas práticas concretas e na valorização da experiência. Estes são princípios equivalentes à filosofia do pragmatismo, cujos principais representantes são: James (1979), Dewey (1971) e Rorty (1982). Essa confluência entre o pensamento pragmatista e a pedagogia da competência implica no fortalecimento da ideologia da racionalidade técnica, própria do sistema capitalista, que valoriza a técnica e o utilitarismo em detrimento de valores humanitários e sociais.

Uma vez revisitado o panorama recente da pedagogia da educação profissional no Brasil, é preciso repensá-la e buscar alternativas para a construção de uma nova pedagogia, voltada para os interesses dos trabalhadores e não fundada nos ditames de um mercado compulsivo. Uma pedagogia segundo a dialética teoria e práxis, em prol da educação 
humanizante e não alienada, que ofereça formação para a vida produtiva, mas que não se retenha a ela e sim a ultrapasse pela proposta de um ensino integral, que englobe política, filosofia, ética e demais conteúdos.

Em busca de novas perspectivas de ensino, a filosofia da práxis pode muito contribuir, assim como o modelo de escola unitária pensada por Gramsci, como uma possibilidade que visa à formação integral do homem por meio de um modelo único de escola, diferenciando-se do atual modelo de educação profissional que se encontra fragmentado em suas múltiplas instituições.

\section{A FILOSOFIA DA PRÁXIS}

A educação profissional incorporada ao modelo por competência, como analisada anteriormente, toma uma dimensão pragmatista e ideológica, cuja preocupação está em formar, conforme os parâmetros da racionalidade técnica. A pedagogia da competência, ao reproduzir através do ensino a lógica da produção capitalista, acaba por revelar sua função desqualificante, similar ao da pedagogia da fábrica, que, segundo Kuenzer (1995), é a redução da prática educativa a um fator técnico de produção, por meio de uma pedagogia criada pelas necessidades do desenvolvimento capitalista e não pelos trabalhadores.

O princípio da racionalidade técnica presente na pedagogia da competência transparece o que Cruz (1999, p.181) chama de ideário moderno da organização do trabalho humano, cujo enfoque está na "formação de um homem dotado de qualidades para sua completa utilização no mundo do trabalho". Para o autor, a atividade profissional passou a representar um fim último. O ideário pragmatista, fincado na racionalidade técnica e presente na educação profissional, contribui para a alienação e para o fetiche do aluno, uma vez que:

Representa uma camuflagem das contradições das condições sociopolíticas em que vive a sociedade, pois o que se prega é o aperfeiçoamento da sociedade (e não a sua mudança) através de tecnologias apropriadas (CRUZ, 1999, p.185).

Portanto, há que se rever o modelo da pedagogia da educação profissional para que ela se torne democrática e verdadeiramente socializadora. Um caminho possível para a superação do modelo das competências, baseado nos princípios do pragmatismo, que vem preparando o trabalhador restritamente para a prática da vida produtiva, é pensar o processo de formação profissional pela perspectiva da filosofia da práxis e é também fundamentar a educação para o trabalho pelo viés da ação social transformadora. Segundo Martins (2004, p.58), "a práxis compreende a dimensão autocriativa do homem, manifestando-se tanto em sua atividade objetiva, pela qual transforma a natureza, quanto na construção de sua própria subjetividade". Assim, por meio da práxis é possível arquitetar a formação do trabalhador na perspectiva ampla do ser social, pertencente ao gênero humano.

No Dicionário do pensamento marxista, Petrovic (1993) considera a práxis como sendo atividade especificamente humana, e a conceitua da seguinte forma:

A ação, a atividade, e no sentido que lhe atribui Marx, à atividade livre, universal, criativa e autocriativa, por meio da qual o homem cria (faz, produz), e transforma (conforma) seu mundo humano e histórico e a si mesmo. (PETROVIC, 1993, p.292). 
No sentido marxista, a práxis é a meta da verdadeira filosofia e por meio dela é possível pensar a revolução, pois a transformação das circunstâncias e da atividade humana ou a autotransformação só pode ser concebida e racionalmente entendida como práxis revolucionária. A filosofia da práxis é antagônica à filosofia do pragmatismo, pois se baseia no princípio da unidade entre teoria e práxis, em que a práxis não é a supremacia da prática pela teoria e sim a visão da teoria como uma das formas de práxis. Para Petrovic (1993), a filosofia da práxis alia "crítica teórica e a transformação revolucionária prática" em prol da abolição da alienação.

Marx (1979), fundamentado na filosofia da práxis e em contraposição à concepção do trabalho alienado, coloca que o verdadeiro sentido do trabalho, em sua condição ontológica, é o de centralizador da humanização. Pensar a educação profissional num sentido ontológico é pensar na transposição do ensino pragmatista para o ensino fundamentado na filosofia da práxis. Martins (2004, p. 59) acredita que a educação principiada na filosofia da práxis é capaz de proporcionar uma formação que auxilia o trabalhador a se objetivar socialmente e é através desta objetivação que ele "desenvolve suas capacidades, suas habilidades, seus sentidos, enfim, as propriedades que lhe conferem condição de ser universal".

Outro fator a ser superado, presente no atual modelo por competências, é a contraposição entre teoria e prática no ensino, em que a prática é supervalorizada em detrimento da teoria. Adorno (1995) considera que a relação entre teoria e prática é mediada pelas relações sociais.

Apesar desta mediação, teoria e prática não são imediatamente identificáveis, podendo estar, até certa medida, dissociadas, causando o desequilíbrio destas relações. Para Kuenzer (2004), a disparidade dentro do modelo por competência referente à relação teoria e prática implica na desarticulação entre saber para o mundo do trabalho e saber para o mundo das relações sociais, contudo a educação concebida como práxis poderia amenizar tal disparidade.

Práxis enquanto processo resultante do contínuo movimento entre teoria e prática, entre pensamento e ação, entre velho e novo, entre sujeito e objeto, entre razão e emoção, entre homem e humanidade, que produz conhecimento e por isto revoluciona o que está dado, transformando a realidade (KUENZER, 2004, p.90).

A concepção de práxis seria uma alternativa importante para a rearticulação entre teoria e prática, uma vez que visa à formação do homem como um todo. Para Martins (2004, p.66), a função primordial da escola é socializar os conhecimentos historicamente construídos e a educação por competência, não tem conseguido atender esta demanda social, ao se fixar na "centralização das esferas do cotidiano, do imediatamente visível e acessível". Muitas vezes, esta prática pedagógica, por desclassificar os conhecimentos sociais que ultrapassam o imediatismo da produção, favorece a visão de naturalização da relação capital trabalho. Porém, Kuenzer (2004) afirma que o modelo de educação profissional como práxis atenderia aos anseios da classe trabalhadora, o que representaria uma proposta de autonomia para o trabalhador. De "instrumento de submissão dos detentores da força de trabalho às diretrizes do mercado", como aponta Saraiva e Masson (2003, p.46), passaria a "instrumento de luta contra-hegemônica". No sentido de adequar o modelo de educação profissional em prol de uma educação emancipadora de trabalhadores, escreve Kuenzer: 
Os conteúdos sobre as determinações sociais, políticas e econômicas que levaram à globalização da economia, à reestruturação produtiva e às novas relações entre Estado e Sociedade, precisam ser apropriados pelos trabalhadores, para que desenvolvam sua capacidade de análise das relações sociais e produtivas e das transformações que ocorrem no mundo do trabalho (KUENZER, 2004, p.92).

Para que o ensino no viés da filosofia da práxis seja possível, é necessário haver uma mudança na proposta curricular da educação profissional. O currículo atual, ao enfatizar conteúdos baseados num cotidiano fetichizado, acaba por esvaziar valores e potencialidades humanas, o que um currículo baseado na práxis poderia oferecer. Uma mudança significativa, por exemplo, pode começar pelo ensino da história do trabalho, pois os alunos precisam se inserir na história das gerações passadas e perceber como o trabalho foi sendo sistematicamente organizado nas sociedades. Para Martins (2004), o ensino dos conhecimentos históricos auxilia na autocompreensão do aluno como ser participante da história:

Para que os indivíduos se objetivem como seres humanos, é preciso que se insiram na história, inserção esta que se dá pelas apropriações das objetivações resultantes das atividades das gerações passadas (MARTINS, 2004, p.58).

Semeraro $(2005$, p.3) afirma que a filosofia da práxis é baseada na "atividade teórico-política e histórico-social dos grupos subalternos que procuram desenvolver um programa de ação dentro do contexto em que vivem". A educação baseada na filosofia da práxis então se preocupa com a autonomia, com o pensamento novo e independente e que contenha em si todos os elementos essenciais para uma concepção global de mundo. Para Semeraro (2005, p.5), a abrangência da filosofia da práxis reside em três principais aspectos: 1) práxis técnico-produtiva, por fazer do trabalho a "célula histórica" da formação do ser pela mediação com a natureza e com os outros homens; 2) práxis científico-experimental, que é ciência e seus experimentos em prol da humanização do mundo e a expansão da democracia; e 3) práxis histórico-política, que é a mediação entre superestrutura e infraestrutura, e entre Estado e sociedade civil.

A educação profissional, concebida pela filosofia da práxis, é uma alternativa que compreende o ensino do trabalho em suas múltiplas facetas. Este ensino englobaria, além da técnica profissional, a filosofia e a política. Estas importantes áreas do conhecimento, bem articuladas, contribuem para a verdadeira autonomia e para a construção de uma nova forma de sociedade. Semeraro (2005) afirma que esta concepção, diferentemente da corrente pragmatista, não separa o agir da prática e nem o mundo material da esfera das ideias. Nela, a individualização do conhecimento não está colocada, pois o conhecimento contribui para a mediação entre indivíduo e a construção de um projeto coletivo de sociedade.

Ao analisar a realidade atual da educação profissional, na forma esfacelada e fetichizada na qual se encontra, é difícil visualizar uma proposta de saída partindo dela. Seu status dual e o vínculo estreito com o capital demonstram a quase impossibilidade de solucioná-la, uma vez que se encontra locada numa sociedade imbricada de problemas políticos e econômicos. Porém, sua intriga problemática induz a pensar numa outra escola para o trabalho, fundada na filosofia da práxis, totalmente diferente da que está colocada, a saber, a escola unitária proposta por Gramsci (1979). 


\section{A ESCOLA UNITÁRIA DE GRAMSCI}

O contexto histórico em que Gramsci pensou a escola única foi num momento histórico-econômico e filosófico não tão diferente do nosso, no qual a sociedade já passava por uma crise profunda da tradição cultural e da concepção da vida e do homem. Aquele início de século $\mathrm{XX}$, em que Gramsci se situava, representou um marco de intensa fragmentação, não só dos processos produtivos, mas do homem também. A racionalidade produtiva do taylorismo e do fordismo era um dos motores que fortaleciam esta fragmentação, separando radicalmente o intelectual e o produtivo. A escola, como reflexo social desta história, encontrava-se num processo caótico de particularização do saber.

No quadro de particularização do saber, a educação de orientação humanista geral, fundada sobre a tradição greco-romana, vigorante até então, já não era propícia para o modelo escolar. A escola abrangente torna-se desinteressante e imprópria para todos, exceto aos que não precisavam se preocupar em profissionalizar-se e podiam se ocupar da vida acadêmica. A explícita particularização do saber otimizava o dualismo escolar, ao qual dividia a escola em clássica e profissional, sendo que, a primeira se destinava às classes dominantes e aos intelectuais e a segunda, às classes instrumentais.

Gramsci (1979) argumentava que a crise da educação e a consequente fragmentação do ensino ocorreram em virtude do processo de transformação da indústria. Para ele, o aperfeiçoamento industrial divide ainda mais as qualificações entre os setores de baixa operação e o de comando já existentes. Surge um novo setor intermediário que é a colocação do profissional técnico. Este novo trabalhador deve ser operário, porém dotado de determinadas qualificações para exercer seu posto. Em detrimento desta ocupação, Gramsci (1979) afirma que houve a proliferação de inúmeras escolas profissionais, cada qual preocupada em estabelecer o ensino voltado para a satisfação de interesses práticos imediatos da produção.

Para Gramsci (1979), a diversificação das escolas profissionais contribui para a perpetuação do dualismo escolar, implicando nas desigualdades dos grupos sociais. As escolas se propagavam como democráticas por oferecer várias possibilidades de segmentos de qualificação. Gramsci (1979) desmascara esta argumentação, pois percebe que as escolas se restringem ao ensino de determinadas técnicas, não oferecendo princípios de filosofia e de educação política, tão necessários ao exercício da verdadeira democracia.

$\mathrm{O}$ aspecto mais paradoxal reside em que este novo tipo de escola aparece e é louvada como democrática, quando, na realidade, não só é destinada a perpetuar as diferenças sociais, como ainda a cristalizá-las em formas chinesas. (GRAMSCI, 1979, p.136).

O discurso sobre a forma de democracia oferecida pela educação profissional, criticado por Gramsci (1979), ainda é uma realidade atual. A LDB institui para o ensino técnico a possibilidade de ser desenvolvido de forma integral, concomitante ou sequencial. Ao propor diferentes fragmentos para este nível de ensino, argumenta que são formas democráticas de profissionalização, uma vez que possibilitam múltiplas formas de qualificação. Gramsci (1979) posiciona-se contra esta proposta de diferenciações no ensino, argumentando sua não-democratização.

Gramsci (1979) infere e diz que é preciso romper com a estrutura fragmentada do sistema escolar e com o dualismo existente que predestina às pessoas de acordo com a classe social. Para ele, isso só será possível na medida em que se evitar a multiplicação 
destas escolas profissionais. Defende ele, a escola unitária, uma estrutura de ensino que agruparia o que hoje corresponde a educação básica e o ensino médio, de forma única formativa, cujo objetivo é o de educar para as atividades intelectuais e manuais de maneira integral. Assim, ele propõe a escola unitária:

Escola única inicial de cultura geral, humanista, formativa, que equilibre equanimemente o desenvolvimento da capacidade de trabalhar manualmente (tecnicamente, industrialmente) e o desenvolvimento das capacidades de trabalho intelectual. (GRAMSCI, 1979, p.118).

Para Gramsci (1979), a escola unitária seria única, pois paralela a ela não existiriam outras fragmentações de unidades de ensino. Nesta perspectiva, as escolas de educação profissional não existiriam mais da forma que estão estabelecidas hoje, pois o ensino profissional estaria agregado à escola única ou ao ensino superior. A escola unitária, além de oferecer o ensino geral, forneceria também a preparação pré-profissional a ser aperfeiçoada numa etapa de educação posterior que seria o ensino superior. Pelo trabalho escolar, seria possível perceber o perfil vocacional dos alunos. A partir daí, oferecer-se-ia orientação profissional. Gramsci (1979) defende a introdução do ensino profissional de forma integrada à escola unitária para que este aluno, ao concluí-la, não fique ao acaso das universidades ou dependente do aprendizado pela prática produtiva. Por isso, haveria a possibilidade também de o aluno sair da escola unitária e ir direto para a vida produtiva, pois a escola ofereceria forte base educacional para tal.

$\mathrm{Na}$ escola única, a organização da carreira escolar se dá de acordo com a idade escolar e conforme o desenvolvimento intelectual e moral dos alunos. Também deverá ser fundamentada levando em consideração os fins que se pretende alcançar. Para a efetivação da escola unitária, Gramsci (1979) argumenta sobre a importância da ampliação da escola, devendo esta ser pública e mais complexa também, voltada para a educação e para a formação das novas gerações sem divisões de grupos ou castas. Ela deverá ser ativa, portadora de uma educação humanista e direcionada para o desenvolvimento da socialização e da autonomia.

A escola unitária ou de formação humanista (entendido este termo,
"humanismo", em sentido amplo e não apenas em sentido tradicional) ou
de cultura geral deveria propor a tarefa de inserir os jovens na atividade
social, depois de tê-los levado a um certo grau de maturidade e
capacidade, à criação intelectual e prática e uma certa autonomia na
orientação e na iniciativa (GRAMSCI, 1979, p.121).

A estrutura da escola unitária deverá ser a de uma escola colégio, com dormitórios, refeitórios, bibliotecas especializadas, auditório para seminários. O ensino deverá ultrapassar os conteúdos elementares para oferecer noções sobre o Estado e sobre a organização da sociedade.

Estes conteúdos precisam ser despojados de todas as formas de misticismo, que Gramsci (1979) chama de visão "folclórica", que é a visão do senso comum. A escola unitária é diferenciada da escola burguesa, pois seu principal objetivo é a formação para a autonomia, baseado num projeto de coletividade e não numa formação para o individualismo e para uma sociedade meramente produtivista. Além destes, outros fatores diferenciam a escola unitária: 
Do ensino quase puramente dogmático, no qual a memória desempenha um grande papel, passa-se à fase criadora ou de trabalho autônomo e independente; da escola com disciplina de estudo imposta e controlada autoritariamente passa-se a uma fase de estudo ou de trabalho profissional na qual a autodisciplina intelectual e a autonomia moral são teoricamente ilimitadas. (GRAMSCI, 1979, p.123)

$\mathrm{O}$ conceito de equilíbrio entre ordem social e ordem natural sobre o fundamento do trabalho, da atividade teórico-prática do homem, cria os primeiros elementos de uma intuição do mundo liberta de toda magia ou bruxaria, e fornece o ponto de partida para o posterior desenvolvimento de uma concepção histórico-dialética do mundo. (GRAMSCI, 1979, p.130).

A escola única proposta por Gramsci $(1979$, p.136) compreende o trabalho para além das esferas produtivas do capitalismo, na qual o estudo deve ser desinteressado, "não deve ter finalidades práticas imediatas" e sim ser rico de noções gerais concretas e abrangentes. Apesar de ser estruturada a partir das bases da escola já existente, a escola única é socialmente inovadora, pois propõe uma educação que centralize o trabalho no seu sentido ontológico, concebendo-o como princípio educativo, socializador e criativo.

A escola unitária projetada por Gramsci (1979) é ativa e criadora e trata-se de uma escola inovadora para o sistema escolar de então. Ela objetiva a superação do dualismo educacional que, por muito tempo, vem efetivando a formação de classes distintas. Também propõe suplantar as dicotomias de formação geral e específica, humanista e técnica, teórica e prática dentre outras. A escola unitária, baseada no princípio educativo do trabalho, permite a ampla formação cultural inicial, com preparação pré-profissional, em vista da formação humanitária e do desenvolvimento omnilateral ${ }^{l}$ do aluno, que é o desenvolvimento mental, físico e técnico.

Não há dúvidas de que a escola unitária, proposta por Gramsci no início do século $\mathrm{XX}$, é um grande referencial para a educação. Porém, pensar sua implementação no contexto atual é algo ainda distante, pois, para que ela se efetive, de fato, são necessários grandes investimentos públicos na sua infraestrutura, e esta mobilização pressupõe uma política que esteja voltada para todos, sem discriminação, o que ainda não está dado. Os inúmeros segmentos da educação profissional existentes deveriam se fundir, juntamente as escolas de ensino fundamental e médio, para então dar lugar à escola única, essencialmente democrática.

\section{CONSIDERAÇÕES FINAIS}

Enquanto a proposta da escola unitária não for possível, devido ao desmonte da educação para o trabalho na sociedade contemporânea, é preciso continuar pensando em caminhos alternativos para a educação profissional. Considerando que este segmento de ensino qualifica trabalhadores em larga escala, é necessário olhá-la com maior interesse. Este exercício compreende repensar criticamente sua pedagogia que, ancorada nos

1 Saviani (1994) esclarece que a formação omnilateral do homem, no sentido marxista, é o que desenvolve ao máximo o potencial dos indivíduos. Para Lombardi (2005), o conceito de formação omnilateral abrange a formação ampla, integral e flexível, sendo a formação ideal para uma revolução na divisão do trabalho existente na sociedade capitalista. 
princípios da filosofia do pragmatismo, irradia por meio do currículo, da metodologia e da avaliação, os fundamentos da racionalidade técnica.

A racionalidade técnica presente na educação profissional reduz o saber da ciência às dimensões da técnica e submete a formação integral para o trabalho em detrimento da formação meramente tecnicista. Superar a racionalidade presente na educação profissional requer um novo pensar filosófico de sua pedagogia, a superação do modelo de competências para um outro modelo que seja mais abrangente e humanizador. A filosofia da práxis pode nos oferecer uma nova proposta pedagógica em prol de uma educação para o trabalho que supere o ensino fetichizado, que atenda à classe trabalhadora e seja socialmente integradora.

Ao refletir sobre a educação, Gramsci (1979) também estava ancorado na filosofia da práxis, e a considerava importante para a ação política. Por compreender a importância da práxis para a educação, recomendava um ensino que primasse pela união entre filosofia, política e economia. Para Gramsci (1979), o entrelaçamento destes três fatores na educação contribuiria para a formação de sujeitos conscientes de sua realidade social, ancorados na concretude histórica e cientes das contradições existentes, das quais precisa compreender, interagir e modificar. Assim, a educação profissional, ancorada na práxis, pode constituirse em importante meio para a superação da fragmentação e da submissão.

Entretanto, ressalta-se que na educação profissional é primordial o preparo para a vida produtiva. $\mathrm{O}$ que se critica aqui, na pedagogia da competência, é a postura de se educar restritamente para a produtividade, na perspectiva de instrução e adaptação. Ao defender o viés da práxis para a educação profissional, coloca-se um ensino que há de preparar para a produtividade, mas com vistas à demanda da igualdade e não da individualidade e competição, no qual os alunos devem ser conscientes do processo produtivo alienante e do processo produtivo socializador.

Assim, o posicionamento da educação deve ser dialético no sentido de manter o equilíbrio entre a tensão da vida produtiva e a vida social. Uma proposta pedagógica de educação profissional deve conter bases sociais valorativas que vão contra a adaptação e a coisificação do trabalho; que seja a favor da formação de sujeitos sociais ativos, educados para a crítica da sociedade atual e não para a sua conformação, sujeitos que hão de questionar a lógica compulsiva do mercado e não procurar se adaptar a ela cegamente.

Há caminhos possíveis para pensar a educação profissional, partindo de uma pedagogia que ofereça ensino para além da prática do trabalho, que favoreça o refletir de uma práxis para o não conformismo da realidade social. Porém, a conjuntura atual do modelo por competência revela importar-se mais com o exercício imediato da atividade produtiva em detrimento de seus alunos trabalhadores e, em relação ao futuro, sugere o favorecimento dos anseios do mercado mundial por vir. Entretanto, há de se continuar indagando sobre a proposta de formação da educação profissional, em vez de afirmá-la em sua racionalidade instrumental que acaba por manter a disparidade das classes sociais. Por fim, faz-se necessário refletir sistematicamente a pedagogia da educação profissional, desvelando sua realidade, em prol de maior emancipação na educação do trabalhador.

\section{BIBLIOGRAFIA}

ADORNO, T. W. Epilegômenos dialéticos. In: Palavras e Sinais. Petrópoles: Vozes. 1995. 
CRUZ, R. M. Formação profissional e formação humana: os (des) caminhos da relação homem-trabalho na modernidade. In: AUED, B. (org.). Educação para o (des)emprego. 2. ed. Petrópolis: Vozes, 1999.

DEWEY, J. Educação e Experiência. São Paulo: Editora Nacional, 1971.

GOMES, H. O fetiche da pedagogia da competência na educação profissional. 2007. 211f. Dissertação (Mestrado em Educação) - Faculdade de Educação, Universidade Federal de Goiás, Goiânia, 2007.

GRAMSCI, A. Os intelectuais e a organização da cultura. 3.ed. Tradução de Carlos Nelson Coutinho. Rio de Janeiro: Civilização Brasileira, 1979.

JAMES, W. Pragmatismo. In: Willians James. Os pensadores. São Paulo: Abril Cultural, 1979.

KLOVDAHL. A. Racionalismo científico. In: BOTTOMORE, T. Dicionário do pensamento social do século XX. Rio de Janeiro: Jorge Zahar, 1996.

KUENZER, A. Competência como Práxis: Os dilemas da relação entre teoria e prática na educação dos trabalhadores. Boletim técnico do SENAC, Rio de Janeiro. V.30, n.3, set.dez. 2004.

Pedagogia da fábrica: as relações de produção e a educação do trabalhador. São Paulo: Cortez, 1995.

LOMBARDI, J. Educação, ensino e formação profissional em Marx e Engels. In: LOMBARDI, J. Marxismo e educação: debates contemporâneos. Campinas: Autores Associados:HISTEDBR, 2005.

MARTINS, L. M. Da formação humana em Marx à crítica da pedagogia das competências. In: DUARTE, N. (org.). Crítica ao fetichismo da individualidade. Campinas: Autores Associados, 2004.

MARX, K.; ENGELS, F. A ideologia alemã. São Paulo: Ciências Humanas, 1979.

Petrovic, G. Práxis. In: BOtTOMORE, T. Dicionário do Pensamento Marxista. Rio de Janeiro: Jorge Zahar, 1993.

RORTY, R. Conseqüências do pragmatismo. Lisboa: Instituto Piaget, 1982.

SARAIVA, S.; MASSON, M. Competência, qualificação e avaliação: observações sobre práticas pedagógicas e educação profissional. Boletim técnico do SENAC, Rio de Janeiro, V.29, n.2, mai/ago. 2003.

SAVIANI, D. História das idéias pedagógicas no Brasil.Campinas: Autores Associados, 2007.

SAVIANI, D. O trabalho como princípio educativo frente às novas tecnologias. In: FERRETTI et al. Novas tecnologias, trabalho e educação: um debate multidisciplinar. 7. ed. Petrópoles: Vozes, 1994.

SEMERARO, G. Filosofia da práxis e (neo) pragmatismo. Revista Brasileira de Educação. Rio de Janeiro, n. 29, mai/ago, 2005. disponível em: $\langle$ http://www.scielo.br/scielo.php?script=sci_arttext\&pid=S141324782005000200003 $>$. Acesso em: 17 de abril de 2007. 
1 Doutor em Educação pela Faculdade de Educação da Universidade Estadual de Campinas - UNICAMP, área de pesquisa Filosofia e Historia da Educação, sob orientação do Professor Doutor José Luis Sanfelice. Email: eraldo_batista@hotmail.com

2 Mestre em Educação pela Faculdade de Educação da Universidade Federal de Goiás (UFG). Linha de pesquisa: Educação e trabalho. Integrante do Grupo de Estudos: Linguagem e Educação (Projet École) da Secretaria Municipal de Educação de Campinas-SP. Atuou como supervisora de ensino no SENAC-GO e como coordenadora pedagógica no SENAI-DF. Atualmente é professora efetiva da Rede Municipal de Educação de Campinas-SP. E-mail: helica@gmail.com

Recebido: abr/2015 Aprovado: mai/2015 